\title{
Differences in mortality from acute myocardial infarction between coronary care unit and medical ward: treatment or bias?
}

\author{
ROBERT REZNIK, IAN RING, PETER FLETCHER, VICTOR SISKIND
}

\begin{abstract}
To analyse the effectiveness of coronary care units in reducing mortality from myocardial infarction 18 hospitals ranging from large urban teaching hospitals to small country hospitals were stratified into four levels of care. Previous analysis had failed to show significant differences in the overall mortality in hospital among levels. There were significant differences in mortality, however, between those patients allocated to be cared for in the coronary care unit and those in the medical wards in the more advanced hospitals. The differences were largest in the hospitals with the most elaborate facilities (level 1) and non-existent in those with the least (level 4). Several analytical approaches to these observed differences indicated that they were: $(a)$ reduced by adjustment for age and severity of infarction; $(b)$ paralleled by differences in coexisting disease recorded on death certificates; (c) no longer significant at level 1 after allowing for differences in coexisting disease; and $(d)$ not significant at any level after exclusion of patients first diagnosed at necropsy.

These findings suggest that the observed differences in mortality between coronary care units and medical wards are largely due to bias in selection and diagnosis.
\end{abstract}

\footnotetext{
Department of Community Medicine, Royal Prince Alfred Hospital, 2037 Glebe, Sydney

ROBERT REZNIK, MB, BS, deputy director

Cancer Epidemiology and Prevention Unit, Queensland Department of Health

IAN RING, MB, BS, director

Department of Medicine, University of Sydney

PETER FLETCHER, PHD, FRACP, senior lecturer

Department of Social and Preventive Medicine, University of Queensland Medical School

VICTOR SISKIND, PHD, reader in medical statistics

Correspondence to: Dr Reznik.
}

Introduction

Since the introduction of coronary care units within hospitals there have been conflicting reports about their ability to reduce hospital mortality compared with medical wards. ${ }^{1}$ Early reports of lower hospital mortality among patients managed in units have not been confirmed. ${ }^{2}$ Possible causes include reasons for selection for ward care, ${ }^{3}$ temporal differences in the rate of diagnosis, ${ }^{4}$ and improved standards of care on medical wards. ${ }^{1}$ We have already reported a large prospective study of mortality from myocardial infarction in different types of hospitals, which showed no differences among hospitals ranging from those with highly advanced coronary care units to those with comparatively primitive facilities. ${ }^{5}$

Overall mortality was, however, significantly lower in the coronary care units $(17 \%)$ than in the general medical wards $(31 \%)$, and this difference was greatest in those hospitals with the most advanced coronary care units. The difference remained after adjustment for age and other standard prognostic factors. Because of similar overall mortality among hospitals we believe that the differences in mortality between wards and units within hospitals may be due to unrecognised sources of bias such as patient selection. In this report we present data to support this belief.

\section{Patients and methods}

Details of the prospective study have been reported previously. ${ }^{5} \mathrm{We}$ enrolled 2991 patients with suspected myocardial infarction, 2266 of whom had a definite or possible acute myocardial infarction. ${ }^{67}$ They were admitted to 18 hospitals in two states of Australia in 1979 and 1980. Hospitals were stratified into four levels of care. Level 1 comprised university teaching hospitals with expert coronary care units and facilities for cardiac surgery and level 4 were small country hospitals with portable monitors within a general medical ward. Levels 2 and 3 were intermediate. Assignment of patients to unit and ward care groups for analysis was based on the patients' main site of care during the first $\mathbf{4 8}$ hours in hospital. For those who died within $\mathbf{4 8}$ hours it was based on the site where most of their care was given before death. The patients' sociodemographic features, clinical presentation, and risk factors were similar among levels, including similar time from onset of the attack to presentation to hospital. Differences in the mix of cases were adjusted by stratifying patients by age and then subdividing them into five further groups according to risk by the Bain prognostic score. ${ }^{8}$ One patient could not be given a prognostic score and was excluded.

Subsequently a small retrospective study of the original cohort was undertaken to study the difference between mortality in the unit and the 
TABLE I-Number (percentage) of deaths in patients with selected coexisting diseases according to age, level of hospital, and place of care

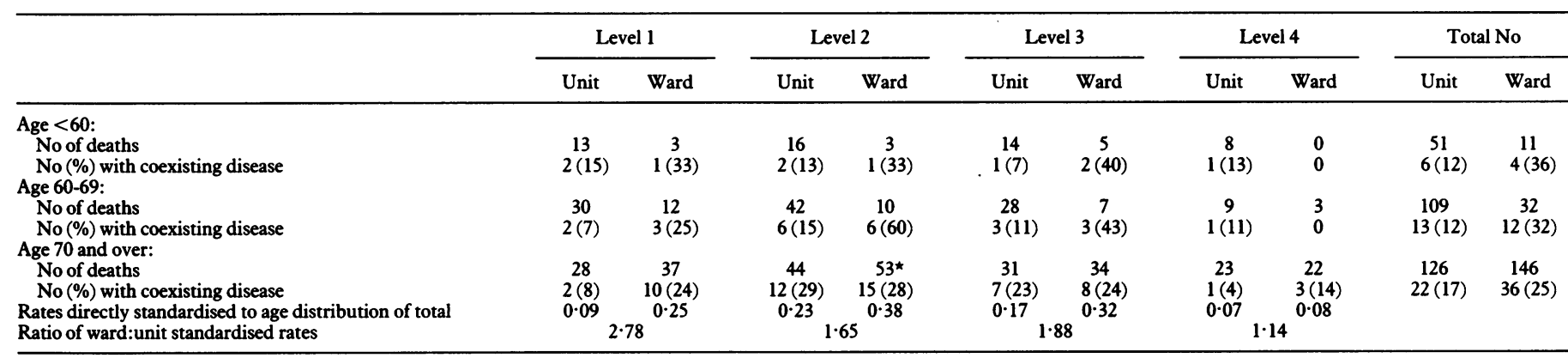

^One patient had no information on death certificate.

TABLE II-Mortality adjusted for coexisting diseases in sample of patients in level 1 hospitals studied retrospectively

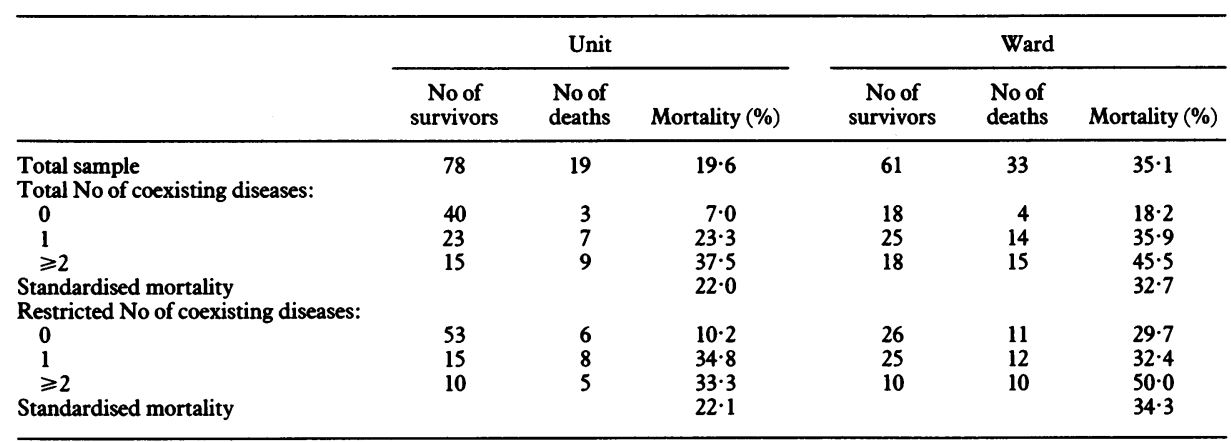

ward among patients in level 1 hospitals, where the greatest difference had been observed. The lowest and highest strata of severity (mortality $<5 \%$ and $>72 \%$ ) were excluded, because there was little difference between unit and ward mortality in these groups. All patients nursed in the ward in level 1 hospitals were selected for study and about the same number of patients nursed in coronary care units were selected at random from the groups of intermediate severity. We selected 96 patients nursed in wards and 99 nursed in units. Medical records were found for 94 of the 96 and 97 of the 99 , giving a total of 191 in the study sample. All diagnoses before or at the time of admission to the study were recorded. The person collecting the data was unaware that the site of care was a crucial factor in the study.

Coexistent diseases were classified as follows: $(a)$ no diagnosis other than myocardial infarction or ischaemic heart disease, or both; $(b)$ other vascular disease; $(c)$ congestive cardiac failure; $(d)$ other heart disease, excluding congestive cardiac failure; $(e)$ hypertension; $(f)$ diabetes mellitus; $(g)$ renal disease; $(h)$ pulmonary disease, excluding thromboembolism; and (i) other diseases, including cancer.

Comparisons of variables within categories were made by $\chi^{2}$ analysis and $\chi^{2}$ analysis of trend. ${ }^{9}$ We used standardised rates for direct presentation in tables and logistic regression for detailed multivariate analysis. ${ }^{10}$ The estimation of risk, odds ratio, used the Mantel and Haenszel test, ${ }^{11}$ and confidence intervals were calculated by Miettinen's method. ${ }^{12}$

\section{Results}

The proportions of patients allocated to be nursed in coronary care units or wards differed among levels. Of 579 patients in level 1 hospitals, 449 $(78 \%)$ were assigned to be nursed in the coronary care unit. Of 342 patients in level 4 hospitals, only $214(63 \%)$ were assigned to the unit. In level 2 and 3 hospitals the numbers were intermediate. Differences among levels were significant (overall $\chi^{2}=26.65, \mathrm{df}=3, \mathrm{p}<0.001, \chi^{2}$ for trend $=22.88, \mathrm{df}=1$, $\mathrm{p}<0.001$ )

Apart from the variable proportions of patients nursed in coronary care units across the levels the groups nursed in units and wards differed in other respects. Their average ages were different. Of 731 patients aged less than 60 years, $644(88 \%)$ were admitted to coronary care units compared with only 390 of $782(50 \%)$ patients aged 70 years or more. Adjustment for age reduced the observed differences between unit and ward mortality. In addition, a larger proportion of patients with more severe infarctions was admitted to the wards. The severity adjusted death rates for levels and for units and wards ${ }^{5}$ are shown in the figure. Adjustment for severity, using the Bain index (which includes age as a factor), also reduced the differences between units

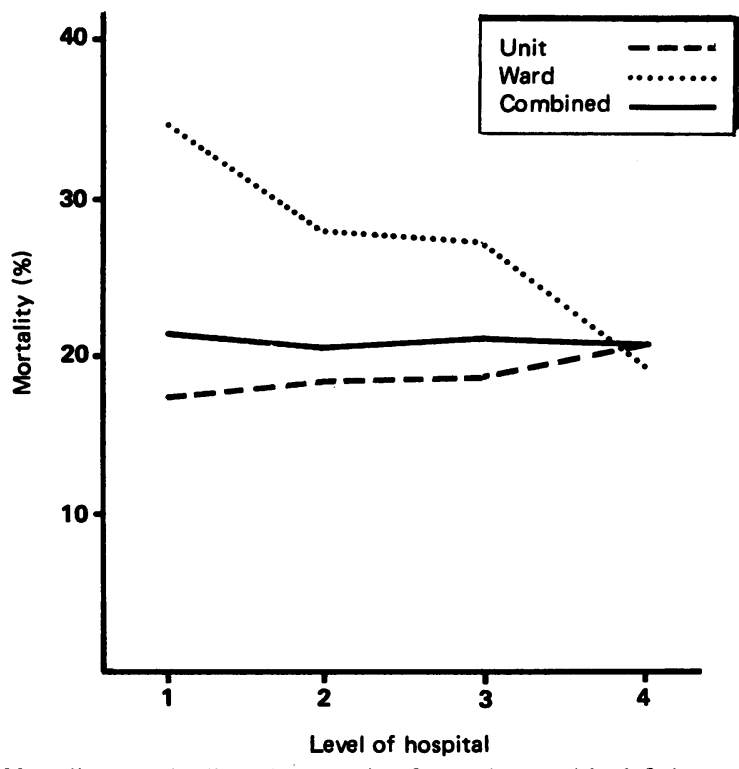

Mortality standardised by severity for patients with definite and possible myocardial infarctions.

and wards compared with the crude death rates, but the difference between unit and ward care in levels 1,2 , and 3 hospitals remained significant. OO Overall hospital mortality also remained similar across levels after adjust- $\infty$ ment.

Twenty other variables not included in the Bain severity index were studied to see if they could have influenced mortality. Three clinical $T$ variables were identified: other concurrent heart disease, treatment with $\bar{O}$ digoxin before admission, and treatment with diuretics before admission. Nevertheless, these additional factors still could not account for the observed difference in unit and ward mortality.

A review of diagnoses given on death certificates suggested that patients selected to be nursed in wards were more seriously ill than those nursed in 8 units. Table I shows the numbers of deaths according to the level of the hospital, the age of the patient, and the site of care, indicating the numbers with coexistent diseases recorded on their death certificates. Patients who 
died after being nursed in the ward had more coexisting diseases in each age stratum. When adjusted to the age distribution of all deaths the differences in numbers of coexisting diseases between unit and ward groups reflected the differences in unit and ward mortality (table I).

A more detailed retrospective review of medical records was then undertaken for patients managed in level 1 hospitals (table II). This level had the largest differences between unit and ward mortality (figure). In the 97 patients nursed in the unit who had been randomly selected for analysis the crude mortality $(19 \cdot 6 \%)$ was slightly higher than the original unit mortality in level 1 for patients within the same strata of severity (15.3\%). Initial analysis included all recorded coexistent diseases. The analysis was then the study solely on the evidence of the necropsy and that such patients would not have been included if they had survived. This might have been particularly noticeable in level 1 hospitals. To counteract this effect all deaths in either unit or ward that were diagnosed by necropsy alone were excluded from the analysis. This meant the exclusion of all those patients who died without either biochemical or electrocardiographic evidence of acute myocardial infarction. Of 475 deaths in the study group, $70(15 \%)$ were therefore excluded. In over $80 \%$ of these cases the attack was not typical.

Table IV shows the mortality stratified for age for all remaining patients. The differences between unit and ward mortality were no longer significant. Compared with the odds ratio when all cases were included, the odds ratio of

TABLE III-Comparison of necropsy rates between wards and units among grades of hospital

\begin{tabular}{|c|c|c|c|c|c|c|}
\hline \multirow[b]{2}{*}{$\begin{array}{l}\text { Level of } \\
\text { hospital }\end{array}$} & \multicolumn{2}{|c|}{ Units } & \multicolumn{2}{|c|}{ Wards } & \multicolumn{2}{|c|}{ Combined rates for units and wards } \\
\hline & $\begin{array}{l}\text { Total No } \\
\text { of deaths }\end{array}$ & $\begin{array}{c}\text { No of } \\
\text { necropsies (\%) }\end{array}$ & $\begin{array}{l}\text { Total No } \\
\text { of deaths }\end{array}$ & $\begin{array}{c}\text { No of } \\
\text { necropsies (\%) }\end{array}$ & $\begin{array}{l}\text { Total No } \\
\text { of deaths }\end{array}$ & $\begin{array}{c}\text { No of } \\
\text { necropsies (\%) }\end{array}$ \\
\hline $\begin{array}{l}\text { Level } 1 \\
\text { Level } 2 \\
\text { Level } 3 \\
\text { Level } 4\end{array}$ & $\begin{array}{r}71 \\
101 \\
73 \\
40\end{array}$ & $\begin{array}{l}9(13)^{\star} \\
29(29) \\
17(23) \\
13(33)\end{array}$ & $\begin{array}{l}52 \\
67 \\
46 \\
25\end{array}$ & $\begin{array}{c}20(38)^{\star} \\
21(31) \\
12(26) \\
4(16)\end{array}$ & $\begin{array}{r}123 \\
168 \\
119 \\
65\end{array}$ & $\begin{array}{l}29(24) \\
50(30) \\
29(24) \\
17(26)\end{array}$ \\
\hline
\end{tabular}

${ }^{\star} \chi^{2}=9 \cdot 69, \mathrm{df}=1, \mathrm{p}<0.005$.

TABLE IV-Age stratified mortality by grade of hospital for patients with definite and possible myocardial infarction after those diagnosed solely at necropsy were excluded

\begin{tabular}{|c|c|c|c|c|c|c|c|c|c|}
\hline \multirow[b]{2}{*}{ Age } & \multicolumn{2}{|c|}{ Level 1} & \multicolumn{2}{|c|}{ Level 2} & \multicolumn{2}{|c|}{ Level 3} & \multicolumn{2}{|c|}{ Level 4} & \multirow[b]{2}{*}{ Total } \\
\hline & Unit & Ward & Unit & Ward & Unit & Ward & Unit & Ward & \\
\hline $\begin{array}{l}<60: \\
\text { No of patients } \\
\text { No (\%) of deaths }\end{array}$ & $\begin{array}{r}188 \\
11(6)\end{array}$ & $\begin{array}{c}11 \\
1(9)\end{array}$ & $\begin{array}{c}221 \\
11(5)\end{array}$ & $\begin{array}{c}18 \\
1(6)\end{array}$ & $\begin{array}{c}162 \\
12(7)\end{array}$ & $\begin{array}{c}23 \\
4(17)\end{array}$ & $\begin{array}{c}63 \\
7(11)\end{array}$ & $\begin{array}{r}30 \\
0\end{array}$ & $\begin{array}{c}716 \\
47(7)\end{array}$ \\
\hline $\begin{array}{l}\text { 60-69: } \\
\text { No of patients } \\
\text { No (\%) of deaths }\end{array}$ & $\begin{array}{c}167 \\
27(16)\end{array}$ & $\begin{array}{c}16 \\
6(38)\end{array}$ & $\begin{array}{c}203 \\
34(17)\end{array}$ & $\begin{array}{c}28 \\
8(29)\end{array}$ & $\begin{array}{c}152 \\
26(17)\end{array}$ & $\begin{array}{c}37 \\
6(16)\end{array}$ & $\begin{array}{c}86 \\
9(10)\end{array}$ & $\begin{array}{c}41 \\
2(5)\end{array}$ & $\begin{array}{c}730 \\
118(16)\end{array}$ \\
\hline $\begin{array}{l}70 \text { and over: } \\
\text { No of patients } \\
\text { No }(\%) \text { of deaths }\end{array}$ & $\begin{array}{c}89 \\
28(31)\end{array}$ & $\begin{array}{c}84 \\
28(33)\end{array}$ & $\begin{array}{c}138 \\
42(30)\end{array}$ & $\begin{array}{c}136 \\
42(31)\end{array}$ & $\begin{array}{c}94 \\
28(30)\end{array}$ & $\begin{array}{c}90 \\
29(32)\end{array}$ & $\begin{array}{c}63 \\
22(35)\end{array}$ & $\begin{array}{c}55 \\
21(38)\end{array}$ & $\begin{array}{c}749 \\
240(32)\end{array}$ \\
\hline $\begin{array}{l}\text { Age standardised mortality } \\
\text { (standardised to age distribution } \\
\text { of entire cohort) }\end{array}$ & 18 & 27 & 18 & 22 & 18 & 22 & 19 & 15 & \\
\hline
\end{tabular}

repeated using a restricted number of coexisting diseases, which excluded hypertension and diabetes because of their association with ischaemic heart disease. There was one or more coexisting disease recorded for $72(77 \%)$ of the patients nursed in wards compared with only 54(56\%) of those nursed in units $\left(\chi^{2}=8 \cdot 40, \mathrm{df}=1, \mathrm{p}<0 \cdot 01\right)$. Using the restricted set of coexisting diseases these figures were $38(61 \%)$ and $57(39 \%)$ respectively $\left(\chi^{2}=7 \cdot 95\right.$, $\mathrm{df}=1, \mathrm{p}<0.01)$. This suggested that coexisting disease influenced the admitting officer's decision to allocate a patient to a ward rather than to the coronary care unit.

The mortality was higher for those with one or more coexistent diseases; their selective effect was allowed for by calculating mortality standardised to the distribution of coexisting diseases in the total sample. This reduced the difference between unit and ward mortality by about one third, but the patients nursed in the ward still had a higher mortality. In the sample the crude odds ratio of ward:unit fatality was $2 \cdot 2(95 \%$ confidence interval $1 \cdot 15$ to $4 \cdot 28$ ). After adjustment for all coexisting diseases and their severity it was 1.78 (95\% confidence interval 0.90 to 3.53 ), and for the restricted set of coexisting diseases it was 1.87 (95\% confidence interval 0.96 to 3.64 ). Thus after adjustment for coexisting diseases the difference in unit and ward mortality in this small sample was not statistically significant. Quite large differences, however, could not be excluded.

Another explanation for the observed differences between unit and ward mortality might be diagnostic detection bias. The availability of diagnostic information among the 2991 suspected attacks was similar among levels of hospital. The history of the attack was known for all but two patients, and it was typical of acute myocardial infarction in $2140(71 \%)$. There were two or more estimations of cardiac enzyme activity available for $2578(86 \%)$ attacks. There were two or more electrocardiograms available for 2611 (87\%) attacks. The overall necropsy rate was also similar among levels of hospital but varied between unit and ward in each level (table III), particularly levels 1 and 4. A significant difference was found only in level 1 hospitals, in which necropsies were more commonly performed for patients from the ward $\left(\chi^{2}=9.69\right.$, $\mathrm{df}=1, \mathrm{p}<0.01$ )

The possibility therefore existed that patients might have been included in death between ward and unit was reduced from $2 \cdot 20$ to 1.38 in level 1 hospitals $(95 \%$ confidence interval 0.81 to 2.37 ), from 1.46 to 1.18 in level 2 hospitals ( $95 \%$ confidence interval 0.76 to 1.83 ), from 1.28 to 1.19 in level 3 hospitals ( $95 \%$ confidence interval 0.74 to 1.94 ), and from 0.79 to 0.75 in level 4 hospitals (95\% confidence interval 0.39 to 1.41 ). Thus the small difference that remained in the mortality adjusted for age between unit and ward care in levels 1,2 , and 3 hospitals was no longer significant. These results did not change when analysis was further restricted to only those patients who had a definite myocardial infarction, among whom the exclusion of patients diagnosed at necropsy gave similar odds ratios. The analysis was repeated for those with definite infarctions and for those with definite or possible infarctions using the Bain prognostic stratification, and similar results were obtained.

This detection bias did not affect the comparisons among levels of hospital as the proportion of deaths at each level that was diagnosed by necropsy alone did not differ significantly $\left(\chi^{2}=6 \cdot 20, \mathrm{df}=3, \mathrm{p}>0 \cdot 10\right)$.

\section{Discussion}

These results suggest that two biases may account for most, if not all, the observed differences in mortality from myocardial infarction between patients nursed in a coronary care unit and those nursed in a general medical ward. The relative importance of each bias has not been assessed and we have simply shown that when adjustment was made for their effect differences in the observed mortality between units and wards did not reach statistical significance.

The first bias was selection. The proportion of patients allocated to be nursed in coronary care units differed among levels of hospital. Patients allocated to be nursed in wards were significantly older and had more severe infarctions as graded by the Bain prognostic score. Hence adjustment for age resulted in reduced differences in 
mortality between units and wards, and when the severity of the attack was considered the differences in mortality were reduced still further. In addition, other confounding factors were found, consistent with the practice of triage that operated at the point of entry to the hospital. These included a larger number of patients in the wards with histories of cardiac failure and of the use of digoxin and diuretics.

Data on another selection factor, coexistent disease, were not collected prospectively. It was not until the analysis had started that a review of the death certificates suggested coexisting disease as a determinant for selection (table I). The number of coexisting diseases was larger among those patients who died in the ward, especially in the younger age groups. Also the difference in the proportions of those who died with coexisting diseases across levels almost paralleled the difference in mortality observed between units and wards. The importance of coexisting disease in the stratification of severity of illness was noted by Feinstein. ${ }^{13}$ The results of the retrospective review of patients studied in level 1 hospitals presented in table II established, firstly, that coexisting disease was an important determinant of outcome and, secondly, that patients with more coexisting diseases were more likely to be allocated to be nursed on the ward. Emergency room staff in the more advanced hospitals may have been more expert in allocating higher risk patients to be nursed in the ward. This analysis, however, is not conclusive, as the confidence interval about the adjusted odds ratio was too broad to exclude the possibility of a large and clinically important difference. Even if the retrospective review had been extended to hospitals in levels 2 to 4 it is unlikely that the upper confidence limit could have been reduced to below 2 . In addition, the ward:unit ratio of the age standardised proportions of deaths among those with coexisting diseases across levels closely reflected the corresponding ward:unit ratios of standardised death rates. Moreover, it was impossible to quantify from the medical records the extent of functional impairment due to coexisting disease. This may have contributed to the failure to reduce further the mortality differences between the two groups.

The conclusion that selection bias is an important explanation of the observed differences in mortality is supported by Zmyslinski $e t$ $a l .^{3}$ They suggested that the higher mortality among patients excluded from coronary care units was due to age, atypical presentation, poor left ventricular function, or appreciable coexisting disease-the same confounding factors as were found in our study.

The clinical decision to admit patients to a coronary care unit or general medical ward may be based on the doctor's judgment of the benefit to the patient of treatment in the coronary care unit, but it may be because the patient poses a diagnostic and therapeutic problem. He has many symptoms, a known history of other diseases including ischaemic heart disease, and possible evidence of decompensation in these organs. It is precisely because such patients present atypically that they are at greater risk of death through compromised cardiac function.

The second bias, detection, has a more complicated explanation. Evidence that this occurred for patients with both definite and possible myocardial infarction is shown in table IV. When patients diagnosed at necropsy were excluded from analysis the significance of the difference in mortality between those nursed in units and those nursed in wards was removed. The existence of this bias in hospital based studies was suggested by Fabricius-Bjerre et al. ${ }^{4}$ Other studies have avoided it by including only patients in whom an attack was suspected on arrival at the hospital. ${ }^{14}$ Such errors in detection must occur; if up to $25 \%$ of infarctions are unrecognised at the time they occur ${ }^{15}$ undoubtedly some are recognised only because the patient's death alerted the diagnostician to the possibility of an attack. This bias was unavoidable in the present study because of the methods of finding cases suggested by community myocardial infarction registers. ${ }^{67}$ These included the review of all deaths that could have been due to infarction.

It is worth restating that there is evidence that the medical wards did provide adequate treatment. The rate of successful cardiopulmonary resuscitation was similar in coronary care units and in medical wards for patients initially managed in the unit, but unsuccessful when it was carried out in the unit or medical ward for patients initially managed in the ward. ${ }^{5}$ The survival rate for resuscitation in the ward among patients originally nursed in the unit was achieved despite the reported poorer prognosis for late ventricular fibrillation. ${ }^{16} 17$

The major differences between coronary care units and wards in the present study emphasise the difficulties facing epidemiologists in mounting studies using this study design. We used standard statistical techniques to adjust for the differences in age, severity, coexisting disease, and diagnostic detection between the two groups. Despite these analyses we could not identify a group of patients who benefited from coronary care, using either successful resuscitation or mortality in hospital as the end point. Nevertheless, it is still possible that the major differences which we identified between patients in units and those in wards obscured a small treatment effect.

The study, the largest undertaken in Australia, had the power to detect at least a $6 \%$ difference between unit and ward care (assuming a true ward mortality of $20 \%$, with $90 \%$ power at the $5 \%$ level). The detection of smaller differences between levels of hospital or unit and ward care were beyond the study's power. If the true benefit of more sophisticated care is indeed smaller it is unlikely that any study could be mounted with sufficient numbers to detect or exclude such an effect with statistical confidence. For example, to detect a difference between treatments, if the true unit mortality was $12 \%$ and the true ward mortality was $15 \%$, over 6000 patients would have to be studied (assuming the same power and significance levels were used). Even this small difference in the effectiveness of treatment may be reflected in larger numbers of lives saved in large populations with high incidences of attacks. ${ }^{18}$ This highlights the dilemma facing clinicians and administrators who are trying to make rational decisions based on objective, scientific evaluation of the effectiveness of costly services. Other ways of reducing the mortality from myocardial infarction require careful consideration if their cost is lower and their potential benefit greater.

The study was funded by the Commonwealth Department of Health. We thank the medical and nursing staff of the 18 hospitals for their generous support, and Professor G Berry for his advice on the analysis and interpretation of results.

\section{References}

I Hill JD, Holdstock G, Hampton JR. Comparison of mortality of patients with heart attacks admitted to a coronary care unit and an ordinary medical ward. Br Med $\mathcal{F} 1977$;ii:81-3.

2 Hofvendahl S. Influence of treatment in a CCU on prognosis in acute myocardial infarction. Acta Med Scand 1971;519:1-78.

3 Zmyslinski RW, Lackland DT, Kiel JE, Higgens JE. Increased fatality and difficult diagnosis of in-hospital acute myocardial infarction: comparison of lower mortality and more easily recognised pre-hospital infarction. Am Heart $f$ 1981;101:586.

4 Fabricius-Bjerre N, Lindholm J, Astvad K, Kjaerulff J. Problem in evaluation of coronary care units. Dan Med Bull 1976;4:163-4.

5 Reznik R, Ring I, Fletcher P, Berry G. Mortality from myocardial infarction in different types of hospitals. BrMed f 1987;294:1121-5.

6 World Health Organisation. Myocardial infarction community registers. (Regional Office for Europe, Copenhagen, 1976.) Public Health in Europe 1977;5:1-232.

7 Joint International Society and Federation of Cardiology/World Health Organisation Task Force on Standardisation of Clinical Nomenclature. Report. Nomenclature and criteria for diagnosis of ischaemic heart disease. Circulation 1979;59:607-8.

8 Bain C, Siskind V, Neilson G. Site of care and survival after acute myocardial infarction. Med J Aust 1981;2:185-8.

Armitage P. Statistical methods in medical research. Oxford: Blackwell Scientific Publications, 1971:207-13, 387.

10 Engleman L. Stepwise logistic regression. In: Dixon WJ, ed. BMDP statistical software. Berkeley: University of California Press, 1981:330-4.

11 Mantel N, Haenszel W. Statistical aspects of the analysis of data from retrospective studies of disease. FNCI 1959;22:719-48.

12 Miettinen OS. Estimability and estimation in case-referrent studies. Am $\mathcal{J}$ Epidemiol 1976;103: 226-35.

13 Feinstein AR. The pre-therapeutic classification of co-morbidity in chronic disease. $\mathcal{F}$ Chronic $\mathrm{Dis}$ 1970;23:455-69.

14 Morris AL, Nernberb V, Roos NP, Henteleff P, Roos LJR. Acute myocardial infarction: survey of urban and rural hospital mortality. Am Heart $\mathcal{F}$ 1983;105:44-53.

15 Kannel WB, Abbott RD. Incidence and prognosis of unrecognised myocardial infarction: an update on the Framingham study. N Engl f Med 1984;311:1144-7.

16 Norris RM, Sammel NL. Predictors of late hospital death in acute myocardial infarction. Prog Cardiovasc Dis 1980;23:129.

17 Lie KI, Liem KL, Hsuilenburg RM, David GK, Durrer D. Early identification of patients developing late in-hospital ventricular fibrillation after discharge from a coronary care unit. A $51 / 2$ year retrospective and prospective study of 1897 patients. Am $\mathcal{F}$ Cardiol 1978;41:674.

18 Goldman L. Coronary care units: a perspective on their epidemiological impact. Int $\mathcal{Z}$ Cardiol 1982;2:287-91.

(Accepted 17 September 1987)

\section{,} .

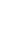

\section{.} .

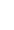
. ,

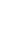
. . (a) 